\title{
Aspecto terminativo: verbos auxiliares no português brasileiro
}

Roberlei Bertucci*1

RESUMO: Este artigo faz um levantamento de algumas características dos auxiliares terminativos em português brasileiro (PB), resume as ideias sobre esses verbos especialmente a partir dos trabalhos de Travaglia (1985) e Castilho (2002), apresenta a abordagem de Portner (2005) para o aspecto e descreve a expressão aspectual desses auxiliares. Portner (2005) considera que o aspecto diz respeito basicamente à relação entre o momento de tópico (T) e o momento do evento (E). Aplicamos tal proposta aos auxiliares terminativos para verificar como podemos descrever a contribuição aspectual desses verbos em $\mathrm{PB}$.

Palavras-chave: aspecto; verbos auxiliares; aspecto terminativo.

ABSTRACT: This paper presents some features of the terminative auxiliaries in Brazilian Portuguese; it summarizes the ideas about them especially from Travaglia's (1985) and Castilho's (2002) works; it shows Portner's (2005) approach about Aspect and describes the aspectual expression of these verbs. Portner (2005) considers that the Aspect is connected basically with the relations between the Topic Time (T) and Event Time (E). We apply this proposal to the terminative auxiliaries to verify how we can describe the aspectual contribution from these verbs in Brazilian Portuguese.

Keywords: aspect; auxiliary verbs; terminative aspect.

Universidade de São Paulo/CAPES. E-mail: roberleib@hotmail.com

1 Agradeço os importantes comentários de Teresa Cristina Wachowicz bem como as observações dos revisores da Filologia e Linguística Portuguesa. Os erros que persistem são exclusivamente meus. Parte dessa pesquisa foi realizada com o apoio financeiro da CAPESCOFECUB (processo no. 2793/09-1). 
1. Introdução

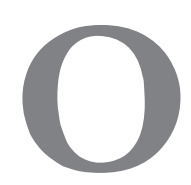

aspecto é um assunto importante, intrigante e um dos mais complexos para os estudos semânticos. Uma série de pesquisas têm sido feitas sobre o assunto, mas ainda assim, há muito o que descrever e analisar quanto à expressão aspectual das línguas naturais, bem como sua interação com outras categorias linguísticas, como o tempo. O estudo dos auxiliares terminativos pode trazer uma contribuição para o entendimento das noções aspectuais em PB.

Neste artigo, fazemos uma abordagem específica sobre a contribuição aspectual de quatro auxiliares do PB: parar, terminar, acabar e chegar. Iniciamos nosso trabalho diferenciando tempo, aspecto e classe aspectual, algo que é bastante comum nas abordagens sobre aspecto desde Comrie (1976). Para essa diferenciação, na seção 2, seguimos as considerações de Portner (2005), para quem as noções temporais podem ser analisadas a partir da relação entre o momento de tópico e o momento de fala e as noções aspectuais entre o momento de tópico e o momento do evento.

As considerações sobre o aspecto terminativo foram retiradas de Travaglia (1985), Castilho (2002) e Longo \& Campos (2002) e estão na seção 3, na qual apresentamos como esses autores definem e explicam esse aspecto em PB. Na mesma seção, utilizamos o teste da negação para mostrar que os auxiliares terminativos carregam consigo a pressuposição do início do evento.

$\mathrm{Na}$ seção 4, em seguida, descrevemos a relação entre os auxiliares terminativos e as classes aspectuais. Veremos que eles não formam boas sentenças ao lado de algumas classes em PB: com acbievements e estados, por exemplo, a restrição é bastante evidente. Analisamos a contribuição aspectual dos auxiliares terminativos a partir das considerações de Portner (2005), na seção 5, aplicando para tais auxiliares a relação entre momento de tópico e momento do evento.

Finalmente, na seção 6, analisamos o verbo chegar, o qual separamos dos outros justamente para defender a ideia de que ele não é um auxiliar terminativo como às vezes encontramos na literatura.

\section{Tempo, aspecto e classes aspectuais}

Antes de nos atermos à questão dos auxiliares terminativos, mostraremos a distinção que há entre tempo, aspecto e classe aspectual. Esses elementos oferecem informações diferentes sobre o evento, tais como o 
momento em que ocorre, seu desdobramento no tempo, completude etc., por isso são importantes no estudo sobre o aspecto.

Para Portner (2005), tempo linguístico ('tense', em inglês) é aquele que indica o momento em que algo acontece no tempo cronológico e aspecto ('aspect', em inglês) são diferentes maneiras de como um evento se desdobra nesse tempo cronológico. A noção desse tempo denominado por Portner (2005) de cronológico é estabelecida pela referência ao momento de fala. Assim, se nos referimos a algo que aconteceu antes do momento de fala, dizemos que esse acontecimento está no passado; algo que acontece ao mesmo tempo que o momento de fala está no presente e algo que acontecerá após o momento de fala está no futuro. Como exemplos de tempo linguístico temos o passado simples, o passado composto e o futuro e como exemplos de aspecto temos o perfectivo e o progressivo. Observemos as sentenças a seguir.

(1) Mary knew French.

'Maria sabia francês.'

(2) Mary knows French.

'Maria sabe francês.'

Portner (2005) afirma que (1) é uma sentença que está no tempo linguístico passado ('past tense'), porque se refere a algo que aconteceu com Maria antes do momento em que a sentença foi pronunciada (antes do momento de fala). Por outro lado, (2) está no tempo linguístico presente ('present tense'), porque se refere a algo que acontece no mesmo instante que o momento de fala. $\mathrm{O}$ autor acrescenta a essas discussões a proposta de Reichenbach (1947) para a interpretação do tempo linguístico em uma sentença. Consideremos (3).

(3) Last month, I went for a hike.

'Mês passado, eu fiz uma trilha.'

Portner (2005) afirma que, de acordo com Reichenbach, para se estudar o tempo linguístico, é necessário estabelecer uma relação entre os momentos de referência (R), de fala (S) e do evento (E). Portner explica que, no caso de (3), S é o momento de seu pronunciamento, E é o tempo de realização da trilha e $\mathrm{R}$ é o mês passado ${ }^{2}$. Dessa forma, no tempo linguístico passado em inglês, o momento de referência precede o mo-

2 Portner (2005) diz que $\mathrm{R}$ pode ser um tempo mais preciso ou menos preciso (p. 143). No caso de (3), é menos preciso, porque engloba todo o mês anterior ao momento de fala. 
mento de fala e é igual ao momento do evento. Essa constatação pode ser dada pela equação $\mathrm{R}<\mathrm{S}, \mathrm{R}=\mathrm{E}$.

Portner (2005) incorpora em sua análise a contribuição de Klein (1994), que substitui referência por tópico, definindo o momento do tópico (T) como "aquele que mostra o momento sobre o qual o locutor está falando" (Portner, 2005, p. 143). Klein defende que a noção de tópico intervalo de tempo sobre o qual o falante faz sua asserção - traz mais intuições sobre o tempo do que a de referência de Reichenbach (1947).

Assim, Portner (2005) propõe uma nova leitura de (3), que substitui referencia por tópico. Pressupondo que em (3) o evento (fazer uma trilha) não tenha durado todo o tempo de tópico (mês passado), temos que $\mathrm{E}$ está contido em $\mathrm{T}: \mathrm{E} \subseteq \mathrm{T}$. O evento (fazer trilha) é realizado num intervalo de tempo menor do que o momento sobre o qual se fala (mês passado). Mas isso pode mudar: há sentenças em que o evento dura mais do que o momento de tópico. É o caso de (4).

(4) Yesterday, Noah had a rash.

'Ontem, Noah estava com uma alergia na pele'.

Nesse caso, o evento (estar com alergia na pele) pode ter começado antes do tópico (ontem), sendo possível que $\mathrm{T} \subseteq \mathrm{E}$, i.e., que o momento de tópico esteja dentro do momento do evento.

$\mathrm{Na}$ discussão sobre aspecto, Portner (2005) diferencia aspecto de classe aspectual (ou Aktionsart). Esta última tem a função de mostrar como a sentença apresenta o desdobramento do evento, especialmente no que diz respeito à duração e completude. Já o aspecto é entendido a partir da relação entre o momento de tópico e o momento do evento.

Uma divisão básica das classes aspectuais é entre eventos e estados. Para os primeiros, temos as seguintes classes: atividades, situações que duram certo tempo, mas que não precisam de ponto final (5); achievements, situações pontuais, que não duram no tempo, e que precisam de um ponto final (6) e accomplishments, situações que duram um certo tempo e precisam de um ponto de final (7). Os estados são situações que permanecem as mesmas no tempo, não envolvem mudança nem exigem ponto final $(8)^{3}$.

3 A maior referência sobre a distinção entre essas quatro classes é Vendler (1967). Para o autor, ter um processo (fases) é uma propriedade de atividades e accomplishments, mas não de estados ou achievements. Por outro lado, ter um ponto final (culminação; telos) é uma propriedade exclusiva de achievements e accomplishments, que se diferenciam apenas pelo fato dos accomplishments serem compostos de processo (fases) 
(5) João correu.

(6) João entrou.

(7) João escreveu a tese.

(8) João é magro.

Portner (2005) lembra a divisão comum nas classes aspectuais entre situações télicas (precisam de um telos, um ponto final) e atélicas (não precisam de um telos) e as possibilidades de inferências dadas por essas classes. No caso de (6), o evento só se completa quando João entra completamente (seja onde for). Se ele estiver entrando e voltar, não podemos inferir que ele entrou. Algo similar acontece em (7): o evento precisa de um ponto final para ser dado como concluído. Assim, o evento só acontece completamente depois que João terminar de escrever a tese. Por outro lado, situações atélicas não precisam de um ponto final para dizermos que foram realizadas. Por exemplo: em (5), o fato de João ter corrido não precisa de um ponto final. Ainda que ele comece a correr e pare, podemos inferir: João correu. Da mesma maneira, o fato de João ser magro (8) não exige um ponto final para a completude do evento.

Portner (2005), no entanto, se concentra na visão de aspecto baseando-se na análise de Reichenbach sobre as relações entre momento de fala (S), momento do evento (E) e momento de referência - ou de tópico (T). O autor afirma que o aspecto se relaciona com o momento do evento $(\mathrm{E})$ e o momento de tópico $(\mathrm{T})$ e exemplifica com o progressivo, em $\mathrm{PB}$ formado com o verbo estar + gerúndio.

(9) João está atravessando a rua.

Para o autor, o progressivo indica, no presente, que o evento continua durante o momento de fala (S). Poderia ser representado assim:

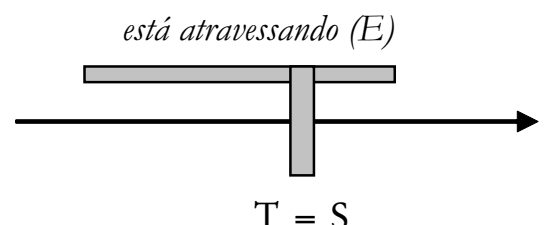

e ponto final, enquanto os achievements são pontuais (sem fases) e só têm uma culminação. Para uma melhor discussão sobre as classes de Vendler, recomendamos ao leitor Rothstein (2004). 
Quanto ao tempo linguístico, estamos tratando do presente, por isso vemos que $\mathrm{T}$ é igual a $\mathrm{S}(\mathrm{T}=\mathrm{S})$. Quanto ao aspecto, a relação se estabelece entre T e E. Nesse caso, T está inserido em E, por isso temos: $\mathrm{T} \subseteq \mathrm{E}$. Para a sentença (9), temos $(\mathrm{T}=\mathrm{S}) \subseteq \mathrm{E}$.

A sentença no passado é analisada da seguinte maneira:

(10) João estava almosando quando telefonei.

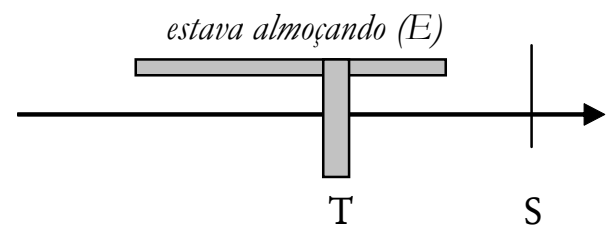

O momento de tópico (quando telefonei) precede o momento de fala, nessa sentença. Por isso, o tempo linguístico (passado) é dado pela equação $\mathrm{T}<\mathrm{S}$. Já o aspecto progressivo mantém a inclusão de $\mathrm{T}$ em E: T $\subseteq \mathrm{E}$. A equação da sentença (10) é: $(\mathrm{T} \subseteq \mathrm{E})<\mathrm{S}$.

Vimos nesta seção que as noções de tempo, classe aspectual e aspecto precisam ser separadas porque tratam de fatores diferentes na análise linguística. A seguir, apresentaremos o que a literatura tem dito sobre auxiliares terminativos; no item 4 , mostraremos a relação entre esses auxiliares e as classes aspectuais em sentenças do PB e, nos itens 5 e 6, aplicaremos a proposta de análise do aspecto de Portner (2005) - relação entre T, E e $\mathrm{S}$ - para os verbos estudados aqui.

\section{Auxiliares terminativos}

Travaglia (1985), Castilho (2002) e Longo \& Campos (2002) foram os autores escolhidos como referência para tratarmos dos auxiliares terminativos. Ao longo do item, o leitor perceberá que as definições dos dois primeiros autores são muito próximas e que Longo \& Campos (2002) parecem se afastar um pouco deles apenas na nomenclatura. Travaglia (1985) diz que o aspecto terminativo ocorre quando a situação é apresentada em seu ponto de término (11) ou em seus momentos finais (12).

(11) Paula sain ao meio-dia.

(12) Paula está terminando de se arrumar. 
Parecem-nos claras as ideias de término apresentadas nas sentenças (11) e (12). Em (11), essa ideia está ligada à flexão verbal: o pretérito perfeito indica que a ação foi encerrada. Em (12), o progressivo (estâ) + terminar de, indicam que a ação de se arrumar está em seus momentos finais.

Uma das questões mais abordadas quando se trata de aspecto é a diferença entre perfectivo e imperfectivo. Seguindo essa tradição, Castilho (2002) apresenta as noções aspectuais nesses dois grupos. No grupo dos perfectivos, está toda ação apresentada em sua completude, "uma ação cujo começo coincide com seu desfecho, tornando-se irrelevantes as fases de seu desenvolvimento [começo, meio e fim]" (Castilho, 2002: 86), como vemos em (13).

(13) Ele fechou os olhos.

Nesse caso, fechou é mostrado em sua completude, sem importar as fases de desenvolvimento. Já no grupo dos imperfectivos, está toda ação em que "é possível reconhecer diferentes fases de seu desenvolvimento" (ibidem), como vemos em (14) e (15).

(14) Ele começou a almoçar.

(15) Ele terminou de almoçar.

Em (14), começou informa que a ação de almoşar está em seu início, enfoca a fase inicial do evento. Nesse caso, portanto, temos o aspecto imperfectivo. $\mathrm{Na}$ sentença (15), terminar enfoca a fase final do evento de almoçar e também temos o aspecto imperfectivo. Castilho (2002) afirma que o terminativo é um subgrupo do aspecto imperfectivo e, numa definição muito próxima à de Travaglia (1985), considera que esse aspecto "assinala os momentos finais de uma duração, o que só é possível em perífrases cujo o V1 [primeiro verbo da perífrase] seja acabar de / por, cessar de, deixar de, terminar de seguido de infinitivo" (Castilho, 2002: 101). Para Travaglia (1985), no entanto, o término não é um subgrupo do imperfectivo, porque estão em níveis diferentes de representação do evento: enquanto o terminativo é usado para expressar uma fase de desenvolvimento do evento (a fase final), o perfectivo e o imperfectivo dizem respeito ao completamento (ou não) desse evento.

Longo \& Campos (2002: 448) dizem haver divergências "quanto à classificação dos verbos indicadores de aspectualidade". Elas denomi- 
nam cessativo o grupo que estamos chamando de terminativo e o definem como aquele em que "o evento é considerado em sua fase final ou término" (idem, p. 449). A definição é próxima às apresentadas por Castilho (2002) ou Travaglia (1985). Como exemplo, elas citam os auxiliares acabar; deixar; parar seguidos de infinitivo, como em:

(16) Ele parou/acabou/deixon de escrever o livro.

Um fato importante que diz respeito aos auxiliares terminativos é que eles acrescentam à sentença a pressuposição do início do evento. Assim, toda vez que usamos um auxiliar terminativo, afirmamos que o evento já começou. De Saeed (2006: 102), tomamos a fórmula para a pressuposição: afirmamos que "uma sentença $p$ pressupõe uma sentença $q$, se i) $p$ é verdadeira, então, $q$ é verdadeira; ii) se $p$ é falsa, então $q$ ainda é verdadeira e iii) se $q$ é verdadeira, então $p$ pode ser falsa ou verdadeira".

Como a negação inverte o valor de verdade de uma sentença, nós a utilizamos para mostrar que, no caso dos auxiliares terminativos, a pressuposição deve ser mantida. A seguir, apresentamos algumas sentenças e suas correspondentes negativas para atestar o fato de estarem pressupondo o início do evento.

(17) a. Ivo parou de escrever o artigo.

b. Ivo não parou de escrever o artigo.

(18) a. Ivo terminou de escrever o artigo.

b. Ivo não terminou de escrever o artigo.

(19) a. Ivo acabou de escrever o artigo.

b. Ivo não acabou de escrever o artigo.

(20) Ivo começou a escrever o artigo.

Os verbos parar, terminar e acabar podem ser chamados "gatilhos lexicais de pressuposição": é a informação lexical (interrupção; término) carregada por esses verbos que indica a existência da pressuposição. Em (17), tanto o fato de Ivo ter parado de escrever o artigo (17a) ou não ter parado (17b) pressupõem que Ivo começou a escrevê-lo (20). Em (18), temos a mesma constatação: o fato de Ivo ter terminado de escrever o artigo (18a) ou não ter terminado (18b) continuam pressupondo que ele começou a escrever o artigo (20). Por fim, em (19), o fato de Ivo ter acabado de escrever o artigo (19a) ou não ter acabado (19b) não alteram a pressuposição, indicada em (20). 
Os auxiliares terminativos enfocam a fase final do evento e, além disso, acrescentam à sentença a pressuposição do início desse mesmo evento. O teste da negação assegurou tal afirmação. No item seguinte, falaremos da relação desses auxiliares com as classes aspectuais.

\section{A relação dos auxiliares terminativos com as classes aspectuais}

As classes aspectuais (também conhecidas como aspecto lexical) estabelecem uma relação importante com o aspecto (gramatical ${ }^{4}$ ). No caso dos auxiliares terminativos, há algumas restrições nessa relação. Vejamos os casos, começando pelo verbo parar:

(21) a. João parou de correr. (atividade)

b. João parou de construir a casa. (accomplishment)

c.?João parou de vencer a corrida. (achievement)

d. "João parou de chegar. (achievement)

e. João parou de chegar atrasado. (atividade)

f. " João parou de ser presidente. (estado)

g. João parou de ser chato. (atividade)

h. O carro parou de ser fabricado. (atividade)

Pelos exemplos, constatamos que parar forma boas sentenças com atividade - (21a), (21e), (21g) e (21h) - ou accomplishment - (21b). Na primeira situação descrita como achievement (21c), a leitura de repetição do fato - o João vencia a corria sempre, agora não vence mais - pode ser possível. Mas, no caso de repetição, vencer a corrida seria descrita como uma espécie de atividade que o João costumava fazer, e não como uma situação achievement. Parar não forma boas sentenças com estados (21f). Parecenos evidente que, embora as situações descritas em (21g-h) possuam o verbo ser em sua composição, ali não estamos tratando de estados, mas de atividades, a saber, a atividade de ser chato (dura um certo tempo e não precisa de ponto final) e a atividade de fabricação do carro 5 . As restrições

4 Sobre a distinção entre aspectos, indicamos Wachowicz \& Foltran (2007).

5 Um revisor tem razão quando nos chama a atenção para o fato de ser chato não ser exatamente uma atividade, mas um estado faseável, como se vê, por exemplo em Cunha (2005). Para o autor, estados faseáveis podem aparecer no progressivo (O João está sendo chato) e não-faseáveis, não podem ("O João está sendo alto). O trabalho de Cunha é bastante valioso nesse sentido e parece ser pertinente quando tratamos de verbos aspectuais. No momento, no entanto, ainda não temos muitas conclusões a respeito e, por simplicidade de análise e desenvolvimento teórico, vamos manter o rótulo "atividade" para predicados como ser chato, porque isso não altera o resultado da nossa proposta. 
com parar não se estabelecem pela telicidade, já que há restrições com situações atélicas (estados) e télicas (acbievements) e sentenças bem formadas com esse tipo de evento também.

O auxiliar terminar apresenta muitas restrições ${ }^{6}$.

(22) a.\#João terminou de correr. (atividade) ${ }^{7}$

b. João terminou de construir a casa. (accomplishment)

c.?João terminou de vencer a corrida. (achievement)

d. "João terminou de chegar. (acbievement)

e. "João terminou de chegar atrasado. (atividade)

f." João terminou de ser presidente. (estado)

g."João terminou de ser chato. (atividade)

h. O carro terminou de ser fabricado. (accomplishment)

Observamos que terminar forma boas sentenças apenas com accomplishments. Nos casos em que a atividade é formada pela composicionalidade dos elementos da frase - (22e) e (22g) - as sentenças também são ruins em PB, diferentemente do que acontece com parar. Por outro lado, assim como parar, terminar também não forma boas sentenças com estados. Não acreditamos que o evento da sentença (22h) possa ser lido como um estado, apesar do verbo ser, mas como um accomplishment ${ }^{8}$. Essa maior restrição de terminar em relação a parar pode estar acontecendo porque terminar carrega a ideia de fim, de término propriamente dito de algum processo e parar, uma ideia de interrupção, que pode ser o fim ou não, por isso pode operar sobre atividades, por exemplo'. Da mesma forma como observa-

6 Bertucci, Paraguassú-Martins \& Lunguinho (2009) mostraram que terminar seleciona eventos (nomes ou nominalizações de eventos também) desde que haja uma certa incrementalidade. Mas isso não trataremos neste artigo.

7 A sentença é possível numa leitura em que o João tem uma corrida pré-determinda (em tempo ou distância). Mas neste caso, tal pré-determinação faz com que o evento seja lido como um accomplishmente não como atividade.

8 Este fato parece reforçar a ideia de que as classes aspectuais são definidas pela composicionalidade da sentença. Vimos que a sentença $(21 \mathrm{~h})$ era uma atividade e a simples alteração do auxiliar, de parar (21h) por terminar (22h), fez com que o evento fosse lido como um accomplishment.

9 Um revisor fez duas importantes observações: atividades como chegar atrasado podem ser tratadas como iteratividade; sendo assim, podemos dizer que parar, mas não terminar, opera sobre eventos iterativos. Na mesma linha, ser chato é um evento com estágios e pode ser interrompido; mas não tem um ponto final, portanto não pode ser terminado, o que faz com que parar possa operar sobre ele, mas terminar não possa. 
mos para o verbo parar, as restrições com terminar não se baseiam só na telicidade, já que há restrições com situações atélicas (estados) e télicas (acbievements) e sentenças bem formadas com esse tipo de evento também. Possivelmente - mas ainda é algo a ser melhor testado - terminar seja uma verbo de interação com processos e, por isso, ou só forma boas sentenças ao lado de accomplishments ou exige leituras de accomplishments para determinadas situações - como acontece em (22a).

O auxiliar acabar apresenta uma leitura aspectual (término) e uma leitura temporal (algo que aconteceu há pouco tempo) ${ }^{10}$.

(23) a. João acabou de correr. (atividade)

b. João acabou de construir a casa. (accomplishment)

c. João acabou de vencer a corrida. (acbievement)

d. João acabou de chegar. (acbievement)

e. João acabou de chegar atrasado. (atividade)

f.?João acabou de ser presidente. (estado)

g.?João acabou de ser chato. (atividade)

h. O carro acabou de ser fabricado. (accomplishment)

A leitura de acabar como auxiliar temporal parece ser possível em todos os exemplos. Tal leitura nos explica o fato de eventos achievements formarem boas sentenças ao lado de acabar, ao contrário do que verificamos com parar e terminar. Em (23c), portanto, a contribuição de acabar é temporal, sinalizando que a vitória de João aconteceu há pouco tempo. A mesma explicação vale para (23d): acabar informa que a chegada de João é um evento que aconteceu pouco tempo antes do momento de fala. No caso se uma atividade como em (23e), a leitura temporal também é a única possível, ou seja, chegar atrasado é um evento que ocorreu instantes antes do momento de fala. Assim como ocorre com terminar em (22e), dizer que acabar informa sobre o término do evento de chegar atrasado é agramatical na língua.

Quanto à leitura terminativa, acabar se comporta de maneira muito próxima à de terminar, porque só forma boas sentenças com accomplishments. Em (23a), acabar informa que a atividade de correr foi finalizada por João embora aqui tenhamos a mesma sensação que tivemos com a sentença (22a) de que a leitura da situação seja de accomplishment. Em (23b), o auxi-

10 Travaglia (2004) apresenta oito valores diferentes para acabar. Para o autor, esses valores fazem parte do processo de poligramaticalização do verbo. 
liar indica que a construção da casa foi concluída. Equivalente ao que vemos com parar e terminar, acabar não forma boas sentenças ao lado de estados. É o que notamos em (23f-g), em que a leitura temporal até pode ser possível, mas a terminativa não. O que dissemos para $(22 \mathrm{~h})$ vale também para (23h): ser fabricado se apresenta como uma atividade, por isso a sentença é bem formada em PB. As restrições com acabar, assim como já dissemos para os dois auxiliares anteriores, não se estabelecem pela telicidade, já que há restrições com situações atélicas (estados) e télicas (achievements) e sentenças bem formadas com esse tipo de evento também.

Descrevemos nesta seção o comportamento dos auxiliares terminativos e mostramos a importância de uma análise que relacione a contribuição aspectual de um verbo com a classe aspectual da situação descrita na sentença. Isso nos permitiu explicar por que algumas sentenças com auxiliares terminativos são estranhas em $\mathrm{PB}$. No próximo item, proporemos uma análise desses auxiliares a partir das considerações de Portner (2005) sobre tempo e aspecto.

5. Análise dos auxiliares terminativos a partir da proposta de Portner

Neste item, nosso objetivo é propor uma análise dos auxiliares terminativos levando em consideração as observações de Portner (2005) sobre aspecto, que apresentamos no item 2. Como observamos naquele momento, $\mathrm{o}$ autor analisa $\mathrm{o}$ aspecto como uma relação entre o momento de tópico (T) e o momento do evento (E). Lembramos que $\mathrm{E}$ refere-se ao momento em que o evento ocorreu no tempo cronológico e que $\mathrm{T}$ é "o momento sobre o qual o locutor está falando" (Portner, 2005: 143). O momento de fala (S) é o momento de pronunciamento da sentença, importante para se estabelecer o tempo linguístico da sentença. Vejamos a sentença a seguir.

(24) a. João parou de almoçar.

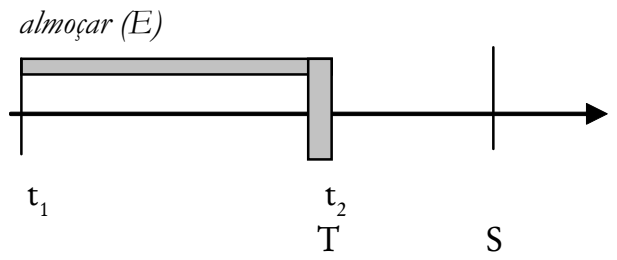


(24) b. João parou de almoçar.

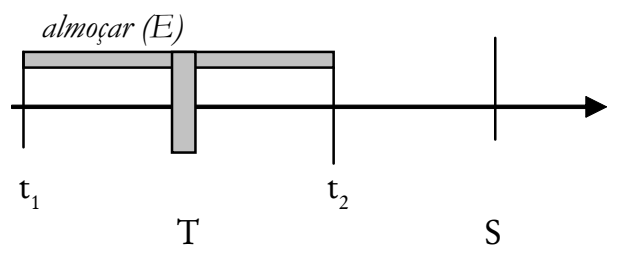

A linha horizontal marca o evento (almoçar), $\mathrm{t}_{1} \mathrm{o}$ início e o $\mathrm{t}_{2} \mathrm{o}$ término desse evento. Precisamos considerar que parar é um auxiliar com dupla leitura na sentença em que se insere. Por isso, parar de almoģar pode significar que a ação foi encerrada (24a), em que $t_{2}$ coincide com $T$, ou que ela foi simplesmente interrompida e recomeçada depois (24b). A equação para o primeiro caso, em que a leitura é terminativa, pode ser assim sugerida: $\left(T=t_{2}\right) \subseteq$ E. Ela explica que o tópico está enfocado no momento final do evento em que está contido. Para o segundo, em que a leitura é de interrupção, pode ser: $\left(T<t_{2}\right) \subseteq E$. Aqui, T não coincide com $t_{2}$, porque estamos afirmando que o evento foi interrompido, por isso não temos uma informação precisa sobre $t_{2}$.

Não estamos seguros ainda das vantagens de se propor uma única equação para parar. Porém, juntando as equações de término e interrupção, podemos sugerir algo como: $\left(\mathrm{T} \mathrm{t}_{2}\right) \subseteq \mathrm{E}$. Isso quer dizer que o tópico pode ser menor (interrompido) ou igual (finalizado) a $t_{2}$, tudo isso contido no momento do evento. Para o verbo terminar, temos o seguinte:

(25) João terminou de almoçar.

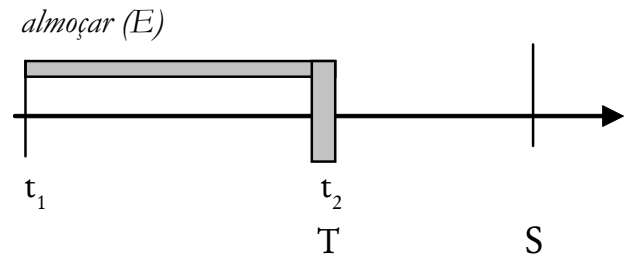

Observamos que o momento do tópico ( $\mathrm{T}$ ) é igual ao final do evento $\left(\mathrm{t}_{2}\right)$, o mesmo que observamos para o auxiliar parar em sua leitura terminativa (24a). Por isso, a equação sugerida para terminar em (25) é a mesma sugerida ao auxiliar parar em (24a): $\left(\mathrm{T}=\mathrm{t}_{2}\right) \subseteq \mathrm{E}$. 
Finalmente, a análise para acabar fica assim:

(26) João acabou de almoçar.

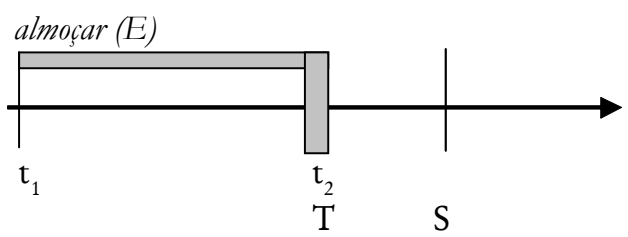

No caso de (26), não nos preocuparemos com a análise temporal, mas somente com a questão do término. Observamos aqui exatamente as mesmas considerações apontadas em (24a) e em (25), isto é, o momento de tópico (T) é igual ao final do evento $\left(t_{2}\right)$ e está contido no momento do evento $(E)$. Por isso, temos a mesma fórmula: $\left(T=t_{2}\right) \subseteq E$. Poderíamos nos perguntar, portanto, por que a língua teria três auxiliares concorrentes para expressar a mesma ideia (de término). Um estudo feito por Travaglia (2004) sobre a gramaticalização de acabar afirma que terminar está "perdendo força no paradigma [marcar aspecto]" (idem, p. 38) e sua ocorrência é bem menor em relação a acabar. Quanto a parar, vimos que seu comportamento é um pouco diferente dos outros dois auxiliares, porque carrega consigo tanto a ideia de término quanto a de interrupção do evento. Isso pode significar que a ocorrência desses três auxiliares na língua pode não ser tão problemática para o $\mathrm{PB}$.

O leitor pode perceber ainda que a pressuposição de início do evento dada pelos auxiliares terminativos - sobre a qual falamos no item 3 - é mantida em todas as equações sugeridas neste item, porque $T$ é igual ou anterior a $t_{2}$, mas está sempre contido em $E$ e é sempre posterior a $t_{1}$. Outro fato importante é que a questão temporal não influencia nas equações apresentadas. Se a sentença (25) fosse para o futuro - João terminará de almocar às $14 \mathrm{~h}$ - teríamos $14 \mathrm{~h}$ como o momento de tópico $(\mathrm{T}) \mathrm{e}$, ao mesmo tempo, como o momento de término do evento de almoçar $\left(\mathrm{t}_{2}\right) \mathrm{e}$ estaria contido no momento do evento $(\mathrm{E})$. A fórmula seria, portanto: ( $\mathrm{T}$ $\left.=\mathrm{t}_{2}\right) \subseteq \mathrm{E}$.

\section{Análise para o verbo chegar}

Em Bertucci (2007), defendíamos que a inserção de chegar na lista dos auxiliares terminativos era equivocada. $\mathrm{Na}$ ocasião, mostramos que esse 
verbo não tem as mesmas propriedades de outros auxiliares de mesma função, como terminar. No presente artigo, mantemos nossa posição e, a fim de analisar a diferença entre tais verbos, repetimos as situações analisadas, mas agora com o auxiliar chegar. O primeiro caso é o referente à pressuposição. Como vimos anteriormente, na seção 3 , os terminativos pressupõem o início do evento e o comprovamos pelo teste da negação. Como podemos ver a seguir, o auxiliar chegar não permite o mesmo tipo de pressuposição.

(27) a. Ivo chegou a escrever o artigo.

b. Ivo não chegou a escrever o artigo.

c. Ivo começou a escrever o artigo.

Diferentemente do que havíamos visto com parar, acabar e terminar, que pressupõem o início do evento mesmo em sentenças em que são negados, chegar não oferece tal leitura, e isso significa que (27b) não pressupõe (27c).

Aplicando o paradigma de relação entre os terminativos e as classes aspectuais que propusemos na seção 4, vemos que chegar tem uma ocorrência mais livre, com poucas restrições.

(27) a. João chegou a correr. (atividade)

b. João chegou a construir a casa. (accomplishment)

c. João chegou a vencer a corrida. (achievement)

d. *João chegou a chegar. (acbievement)

e. João chegou a sair. (acbievement)

f.? João chegou a chegar atrasado. (atividade)

g. João chegou a ser presidente. (estado)

h. João chegou a ser chato. (atividade)

i. O carro chegou a ser fabricado. (atividade)

O único caso em que a sentença com chegar parece efetivamente ruim é (27d), mas vemos que não é por estar associada a uma situação acbievement, mas por haver uma repetição de chegar. Ao lado de sair, que também é achievement, chegar formou uma boa sentença (27e).

A hipótese para essa "liberdade de ocorrência" é a de que chegar não opera sobre o evento em si, mas sobre a sentença. Isso significa que chegar não toma um evento como complemento para retornar uma parte desse evento, o que ocorre com operadores aspectuais como começar, parar ou 
terminar. O que esse verbo parece fazer é ordenar a situação dada como a mais relevante numa dada escala (cf. Bertucci 2007). Essa hipótese se fortalece quando olhamos para a descrição do valor aspectual de chegar em comparação com o que fizemos na seção 5 para os auxiliares terminativos.

(28) Ontem, João chegou a limpar o chão.

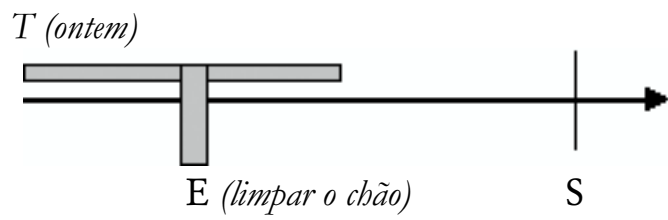

Em (28), E (limpar o chão) está inserido no momento de tópico (ontem). Portanto, temos $\mathrm{E} \subseteq \mathrm{T}$, ou seja, aspecto perfectivo, exatamente o contrário do que ocorre com terminar em (25). O leitor pode perguntar se o fato da sentença estar no passado não pode condicionar a leitura perfectiva. Então, vejamos o exemplo (29).

(29) Quando faz calor, João chega a tomar três banhos por dia.

$T$ (fazer calor)

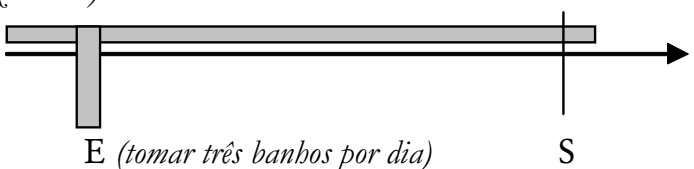

Nesse caso, vemos que o evento tomar três banhos por dia está inserido no tópico fazer calor, o que corrobora a descrição que já havíamos feito para o verbo chegar na sentença (28). Como a sentença está no presente, o momento de fala (S) também está inserido no tópico.

Esses casos nos motivam a continuar as pesquisas com os chamados verbos auxiliares em $\mathrm{PB}$ e, no caso específico de chegar, nos faz levantar a hipótese de que a contribuição aspectual desse verbo seja um certo tipo de perfectivizaçãol telicização da sentença em que ele é um auxiliar.

\section{Conclusão}

Como vimos, os auxiliares terminativos são importantes porque contribuem para uma leitura aspectual específica em PB. Mostramos sua relação com as classes aspectuais, bem como as restrições que ocorrem 
nessa relação e a pressuposição de início do evento revelada pela presença do auxiliar na sentença. Finalmente, propusemos uma leitura para os auxiliares terminativos levando em conta a proposta de Portner (2005), que analisa o aspecto a partir da relação entre momento de tópico e momento do evento. Quando parar indica interrupção, o momento de tópico é anterior ao término, mas continua contido no momento do evento. $\mathrm{O}$ fato de termos inserido parar no rol dos auxiliares terminativos, mesmo sabendo que sua leitura é muito mais de interrupção, se deve ao fato desse verbo ter uma leitura também terminativa, como acreditamos ter deixado claro. Assim, ficou mais fácil compararmos as diferentes leituras dadas pelos diferentes verbos.

Wachowicz (2007) propõe que esses verbos a que estamos chamando de auxiliares terminativos sejam na verdade verbos aspectualizadores, os quais operam sobre eventos. Essa afirmação pode ser importante para o tratamento desses verbos em $\mathrm{PB}$, já que ainda nos falta uma explicação adequada para sentenças como ? A fruta parou de amadurecer; ?O João parou de começar a escrever o livro. Nesses casos, parece haver um conflito de operações que não permitem que as sentenças sejam gramaticais em PB. Em trabalhos posteriores, talvez possamos explicar que tipo de operação esses verbos estão realizando na estrutura da língua e por que algumas dessas operações geram sentenças ruins em PB.

\section{Referências bibliográficas}

BERTUCCI, Roberlei. 2007. A auxiliaridade do verbo chegar em português brasileiro. Curitiba: Universidade Federal do Paraná. Dissertação de mestrado.

BERTUCCI, Roberlei, PARAGUASSÚ-MARTINS, Nize \& LUNGUINHO, Marcus.2009. Denotações nominais e interação com o verbo terminar. Poster apresentado no encontro Discutindo Semântica Formal com Rodolfo Ilari. Campinas: Unicamp.

CASTILHO, Ataliba Teixeira de. 2002. Aspecto verbal no português falado. In: ABAURRE, Maria Bernadete Marques \& RODRIGUES, Ângela. C. S. (orgs). Gramática do Português Falado, v. VIII, Campinas, SP: Editora da Unicamp, p. 83-122.

COMRIE, Bernard. 1976. Aspect. An introduction to the study of verbal aspect and related problems, Cambridge etc., Cambridge University Press.

CUNHA, Luis Felipe. 2005. Reconsidering stative predications, their behaviour and characteristics. Cadernos de Linguistica n. 11, Porto, C.L.U.P. Disponível também: http:// cl.up.pt/conteudos/cadernos/caderno11.pdf

KLEIN, Wolfgang. 1994. Time in language. London: Routledge.

LONGO, Beatriz de O. \& CAMPOS, Odette de S. 2002. A auxiliaridade: perífrases de tempo e de aspecto no português falado. In: ABAURRE, Maria Bernadete Marques \& 
RODRIGUES, Ângela C. S. (orgs). Gramática do Português Falado, v. VIII, Campinas, SP: Editora da Unicamp, p. 445-477.

PORTNER, Paul. 2005. What is meaning? Fundamentals of formal semantics. Oxford: Blackwell Publishing.

REICHENBACH, Hans. 1947. Elements of symbolic logic. New York: The MacMillan Company.

ROTHSTEIN, Susan. 2004. Structuring Events: a study in the semantics of lexical aspect. Oxford: Blackwell.

TRAVAGLIA, Luiz Carlos. 1985. O aspecto verbal no português a categoria e sua expressão. Uberlândia: Universidade Federal de Uberlândia.

(2004). A (poli)gramaticalização do verbo acabar. Letras \& Letras: Uberlândia, n. 20 (2, jul./dez.), pp. 21-56.

VENDLER, Zeno. 1967. Verbs and Times. Linguistics in Pbilosophy. Ithaca: Cornell University Press.

WACHOWICZ, Teresa Cristina. 2007. Auxiliary and Aspectualizer verbs: some syntactic and semantic distinctions. Revista Letras: Curitiba, n. 73, p. 223-234, set./dez. 2007. Editora da UFPR.

WACHOWICZ, Teresa Cristina \& FOLTRAN, Maria José. 2007. Sobre a noção de aspecto. Cadernos de Estudos Lingüísticos (UNICAMP), v. 48, p. 211-232. 